\title{
Potato spindle tuber viroid as Inducer of RNA Silencing in Infected Tomato
}

\author{
Asuka Itaya, ${ }^{1}$ Alexey Folimonov, ${ }^{2}$ Yoshie Matsuda, ${ }^{1}$ Richard S. Nelson, ${ }^{2}$ and Biao Ding ${ }^{1}$ \\ ${ }^{1}$ Department of Plant Biology and Plant Biotechnology Center, Ohio State University, Columbus, U.S.A.; \\ ${ }^{2}$ Plant Biology Division, Samuel Roberts Noble Foundation, Ardmore, OK, U.S.A. \\ Submitted 30 May 2001; Accepted 12 July 2001.
}

\begin{abstract}
Potato spindle tuber viroid (PSTVd), an RNA plant pathogen encoding no known proteins, induces systemic symptoms on tomato plants. We report detection of small RNAs of approximately 25 nucleotides with sequence specificity to PSTVd in infected plants: an indication of the presence of RNA silencing. RNA silencing, however, did not appear to be responsible for the differing symptoms induced by a mild and a severe strain of PSTVd. The unique structural and biological features of viroids make them attractive experimental tools to investigate mechanisms of RNA silencing and pathogen counterdefense.
\end{abstract}

Additional keywords: gene silencing.

RNA silencing is an important mechanism of gene regulation in many organisms, including plants (Bass 2000; Carthew 2001; Lindbo et al. 2001; Matzke et al. 2001; Vaucheret and Fagard 2001). RNA silencing can be subclassified into RNAmediated transcriptional gene silencing (TGS) and posttranscriptional gene silencing (PTGS). RNA-mediated TGS occurs when double-stranded (ds) RNA with sequence homology to a promoter is produced, leading to de novo DNA methylation of the promoter region of the structural gene (Mette et al. 2000). PTGS, on the other hand, (i) yields reduced steady state levels of targeted host or viral cytoplasmic RNA, and to a lesser, but sometimes observable, reduction of nuclear RNA (Lindbo et al. 1993; Montgomery et al. 1998; van Blockland et al. 1994); and (ii) may be mediated through a host-encoded RNA-dependent RNA polymerase (RdRp) and RNA helicase (Cogoni and Macino 1999; Dalmay et al. 2000, 2001; Domeier et al. 2000; Mourrain et al. 2000). A hallmark of RNA-mediated TGS and PTGS is the production of small RNAs of 21 to 23 nucleotides (nt) with sequence specific to the silenced gene (Elbashir et al. 2001; Hamilton and Baulcombe 1999; Mette et al. 2000; Zamore et al. 2000). A plant virus can be both the inducer and target of RNA silencing (Baulcombe 1996; Marathe et al. 2000). RNA silencing is, therefore, believed to

Corresponding author: Biao Ding;

Address: Department of Plant Biology and Plant Biotechnology Center, 207 Rightmire Hall, Ohio State University, 1060 Carmack Road,

Columbus, 43210, U.S.A.;

Telephone: +1-614-247-6077; Fax: +1-614-292-5379;

E-mail: ding.35@osu.edu

A. Itaya and A. Folimonov are co-first authors. play a role in host defense against pathogen infection, as well as in inactivating expression of undesired host genes (Matzke et al. 2001).

Viroids are single-stranded, covalently closed, circular RNA molecules 246 to 499 nt long (Mathews 1991). In striking contrast to viruses, viroids do not encode any proteins and are not known to be encapsidated (Mathews 1991). Wassenegger et al. (1994) demonstrated that Potato spindle tuber viroid (PSTVd) can trigger methylation of PSTVd cDNA sequences stably incorporated into the transgenic tobacco genome. Interestingly, a DNA target of $30 \mathrm{bp}$ is sufficient for this methylation to occur (Pelissier and Wassenegger 2000). The size of the target is similar to the size of the small RNAs produced during RNA-mediated TGS and PTGS. Thus, viroid infection may be a unique system to study RNA silencing, but more information is necessary to establish this experimental system. For example, it has not been reported whether infections of plant tissue with viroids yield the small RNAs associated with RNA silencing. Given that RNA silencing is a defense mechanism against viral infection, it is also of outstanding interest to determine whether RNA silencing could contribute to the varying symptoms elicited by different viroid strains.

To test whether PSTVd could trigger the production of small RNAs, we analyzed PSTVd-infected tomato plants for the presence of small RNAs with sequence specificity to PSTVd. We inoculated cotyledons of 10-day-old tomato plants (Lycopersicon esculentum cv. Rutgers) with in vitro transcripts of two strains of PSTVd, the mild and RG1 (severe) (Owens et al. 1996). Forty nanograms of RNA was used to inoculate each plant. Diethylpyrocarbonate-treated water was used as the mock inoculum. The plants were grown in a growth chamber set for an 18 -h-light $\left(26^{\circ} \mathrm{C}\right) / 6$-hdark $\left(26^{\circ} \mathrm{C}\right)$ cycle. RG1-infected plants started showing symptoms at 17 days postinoculation (dpi) and mild-strain-infected plants started showing symptoms at 25 dpi. Samples from systemic leaves were collected from all inoculated plants at 17 and 25 dpi. Total RNA was isolated from the systemic leaves and PSTVd-specific small RNA was detected essentially as described by Hamilton and Baulcombe (1999), except that total RNA without enrichment of small RNA was loaded on the gel (Hutvágner et al. 2000). Briefly, the RNA samples were separated by electrophoresis through a $15 \%$-polyacrylamide-8-M-urea gel, transferred onto a nylon 
membrane, and cross-linked by UV. A 25-nt DNA oligonucleotide was loaded on the same gel as a size marker. The blotted membrane was prehybridized at $42^{\circ} \mathrm{C}$ for $30 \mathrm{~min}$ and then hybridized with an $\alpha_{-}{ }^{32} \mathrm{P}$ UTP-labeled, minus-strand (-) PSTVd RNA probe overnight at $35^{\circ} \mathrm{C}$. The intensity of each individual band was determined by phosphor-imager scanning, and the relative amounts of RNA were quantified using ImageQuant software (Molecular Dynamics, Sunnyvale, CA, U.S.A.).

We detected small RNAs of approximately $25 \mathrm{nt}$ in both mild-strain- and RG1-infected tomato plants, but not in mock-inoculated plants (Fig. 1 and data not shown). The amount of small RNA was greater in RG1-infected plants than in mild-strain-infected plants (approximately 1.4- and 1.9-fold at 17 and $25 \mathrm{dpi}$, respectively; values represent the mean of three independent experiments). For both strains, the amount of small RNA was higher at 25 dpi than at 17 dpi (2.5- and 3.5-fold higher for mild and RG1 strains, respectively). Also for both strains, the amount of viroid was higher at 25 dpi than at $17 \mathrm{dpi}$ (1.5- and 4.0-fold higher for mild and RG1 strains, respectively; values represent the mean for three independent experiments). Thus, the amount of small RNA and viroid increased with time for each strain. In light of the consistent production of small RNAs in all other RNA-silencing systems, we interpret the presence of PSTVd-specific small RNA in the infected tomato plants as an indication of viroid-induced RNA silencing (VdIRS).

Current models suggest that elicitors of RNA silencing include dsRNAs that are formed during replication of RNA viruses or that are formed from aberrant host RNA templates by an RdRp (Lindbo et al. 2001; Matzke et al. 2001). Biochemical studies employing Drosophila spp. have provided some mechanistic insights into this process. Based on these studies, substrate dsRNAs are cleaved into 21- to 23-nt small RNAs by an RNase III-like nuclease (Bernstein et al. 2001). Strikingly, a target mRNA is cleaved at 21 to 23 intervals, suggesting that the small RNAs derived from the dsRNAs serve as a guide to RNAs targeted for mRNA degradation (Elbashir et al. 2001; Zamore et al. 2000). dsRNAs of greater than $38 \mathrm{nt}$ are necessary to potentiate PTGS (Elbashir et al. 2001).

PSTVd replication involves a rolling-circle mechanism (Branch and Robertson 1984). In this mechanism, the plusstrand $(+)$, circular viroid molecule serves as the initial template for the production of a linear and multimeric (-) RNA. This (-) RNA is then used as the template for the synthesis of a linear and multimeric (+) RNA. The (+) RNA is subsequently cleaved into unit-length RNAs that are circularized to form the mature viroid molecules. Based on these findings, dsRNAs are transiently formed at several stages of PSTVd replication and they could be the target of an RNase III-like nuclease. The observed 25-nt RNAs could be a mixture of the dsRNA derivatives and the target RNA degradation products.

Pelissier and Wassenegger (2000) suggested that the fullsize, mature PSTVd molecules function to induce DNA methylation. In light of our detection of PSTVd-specific small RNAs in the infected tomato, we suggest that such small RNAs could be the alternative RNA forms that induce DNA methylation. This model, consistent with the general idea proposed by Matzke et al. (2001), is attractive because it could explain how a DNA target of $30 \mathrm{bp}$ is sufficient for methylation to occur (Pelissier and Wassenegger 2000). Further studies on VdIRS could provide a critical test of the model.

How does PSTVd evade host gene silencing? Several possibilities can be considered. First, if PSTVd exists primarily as a rod-shaped structure in the cell during its life cycle, extensive base-pairing within the molecule would form a complex secondary structure that prevents recognition by the small RNA guides. The accepted secondary structure does not contain any dsRNA stretches of $23 \mathrm{nt}$ or greater in length; therefore, the final form of the viroid would be an unlikely target for an RNase III-like nuclease. Second, viroids may be bound to cellular proteins to be protected. Third, a viroid may actively suppress RNA silencing either by activating a host protein suppressor of RNA silencing or by directly silencing host genes in the pathway. A recent study identified a calmodulinlike plant protein that functions

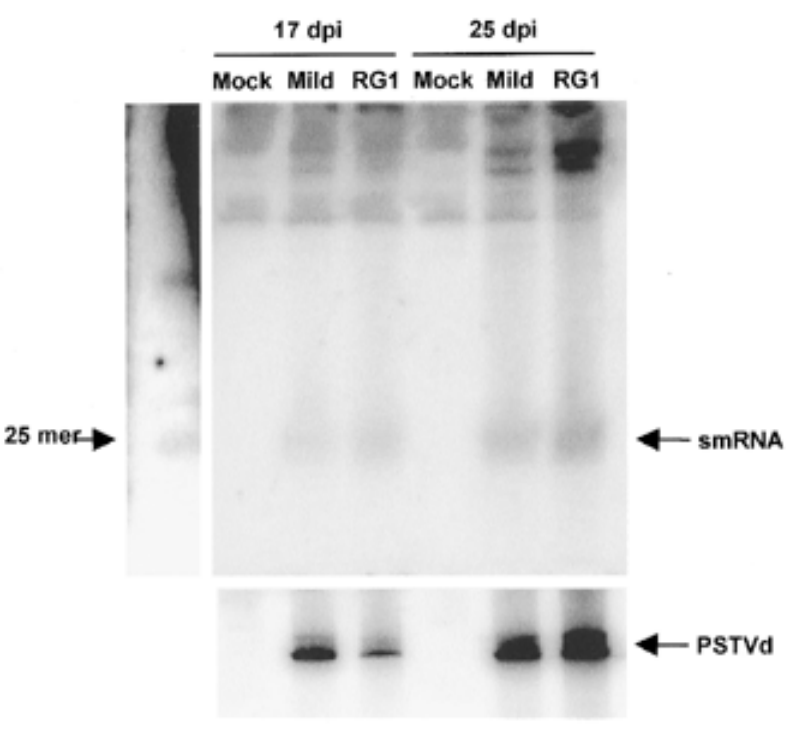

Fig. 1. Upper panels show detection of small RNAs in Potato spindle tuber viroid (PSTVd)-infected tomato plants. Total RNA from indcated plants was isolated using Trizol reagent (Gibco-BRL, Rockville, MD, U.S.A.) and $80 \mu \mathrm{g}$ of total RNA was loaded in each lane. For a size maker, 25-nt PSTVd oligonucleotides were loaded on the same gel (upper left panel). The blotted membrane was prehybridized in ULTR Hyb (Ambion, Austin, TX, U.S.A.) at $42^{\circ} \mathrm{C}$ for $30 \mathrm{~min}$ and then hybridized in the same solution with a PSTVd minus-strand (-) RNA probe labeled with $\alpha-{ }^{32} \mathrm{P}$ UTP at $35^{\circ} \mathrm{C}$ overnight. Small RNAs were detected in mild-strain- and RG1-infected plants, but not in mockinoculated plants (upper right panel). The signal above the 25-nt oligomer came from the RNA probe hybridized to the PSTVd plusstrand (+) RNA that was originally loaded in the adjacent lane as a positive control, but was cut out for imaging purpose. Consistent with Hamilton and Baulcombe's (1999) observations, some nonspecific probe binding (for instance bands in the lanes containing the sample from mock-inoculated plants) occurs at the $35^{\circ} \mathrm{C}$ hybridization temperature, which is necessary to detect the small RNA. Such nonspecific binding is eliminated when hybridization is conducted at $55^{\circ} \mathrm{C}$, which, however, leads to poor detection of the small RNA. The bottom panel shows detection of PSTVd under $55^{\circ} \mathrm{C}$ prehybridization and hybridization conditions with reduced background signals. All lanes in this panel contain the same types of samples as indicated in the upper right panel. Total RNA $(40 \mu \mathrm{g})$ was loaded in each lane. 
as a suppressor of PTGS (Anandalakshmi et al. 2000). Thus, there is an endogenous mechanism with which PSTVd could potentially interact to suppress PTGS. It will be interesting to determine if this host protein is induced during PSTVd infection.

If an increase in the amount of the small RNA is indicative of enhanced RNA silencing, one would expect that the level of PSTVd accumulation and, therefore, symptom severity decrease accordingly. However, this was not observed. Rather, the level of small RNA increased with increased PSTVd accumulation levels and development of symptoms. The results provide support for the hypothesis that selective molecular interactions of different viroid strains with host factors contribute to varying degrees of symptom expression (Owens et al. 1996).

In summary, we have obtained evidence that PSTVd can be an activator and target of RNA silencing. However, the differing symptom severities induced by the two viroid strains were positively correlated with the level of small RNAs produced, indicating that RNA silencing was unlikely to be responsible for the differing disease phenotypes. The many unique features of PSTVd make it a potentially useful tool to investigate the mechanism of RNA silencing, as well as any counterdefenses the pathogen may display.

\section{ACKNOWLEDGMENTS}

We thank R. Owens for providing PSTVd cDNAs. We thank Y. Qi for reading the manuscript. This work was supported by grants from the U.S. Department of Agriculture National Research Initiative Competitive Grants Program (No. 97-35303-4519) to B. Ding and from the Samuel Roberts Noble Foundation to B. Ding and R. S. Nelson.

\section{NOTE ADDED IN PROOF}

While this manuscript was under review, a paper (Papaefthimiou et al. 2001) was published describing results similar to those reported here.

\section{LITERATURE CITED}

Anandalakshmi, R., Marathe, R., Ge, X., Herr, J. M., Jr., Mau, C., Mallory, A., Pruss, G., Bowman, L., and Vance, V. B. 2000. A calmodulin-related protein that suppresses posttranscriptional gene silencing in plants. Science 290:142-144.

Bass, B. L. 2000. Double-stranded RNA as a template for gene silencing. Cell 101:235-238.

Baulcombe, D. C. 1996. RNA as a target and an initiator of post-transcriptional gene silencing in transgenic plants. Plant Mol. Biol. 32:7988.

Bernstein, E., Caudy, A. A., Hammond, S. M., and Hannon, G. J. 2001. Role for a bidentate ribonuclease in the initiation step of RNA interference. Nature 409:363-366.

Branch, A. D., and Robertson, H. D. 1984. A replication cycle for viroids and other small infectious RNA's. Science 223:450-455.

Carthew, R. W. 2001. Gene silencing by double-stranded RNA. Curr. Opin. Cell Biol. 13:244-248.

Cogoni, C., and Macino, G. 1999. Gene silencing in Neurospora crassa requires a protein homologous to RNA-dependent RNA polymerase. Nature 399:166-169.
Dalmay, T., Hamilton, A., Rudd, S., Angell, S., and Baulcombe, D. C. 2000. An RNA-dependent RNA polymerase gene in Arabidopsis is required for posttranscriptional gene silencing mediated by a transgene but not by a virus. Cell 101:543-553.

Dalmay, T., Horsefield, R., Braunstein, T. H., and Baulcombe, D. C. 2001. SDE3 encodes an RNA helicase required for post-transcriptional gene silencing in Arabidopsis. EMBO (Eur. Mol. Biol. Organ.) J. 20:2069-2077.

Domeier, M. E., Morse, D. P., Knight, S. W., Portereiko, M., Bass, B. L., and Mango, S. E. 2000. A link between RNA interference and nonsense-mediated decay in Caenorhabditis elegans. Science 289:19281930.

Elbashir, S. M., Lendeckel, W., and Tuschl, T. 2001. RNA interference is mediated by 21- and 22-nucleotide RNAs. Genes Dev. 15:188200.

Hamilton, A. J., and Baulcombe, D. C. 1999. A species of small antisense RNA in posttranscriptional gene silencing in plants. Science 286:950-952.

Hutvágner, G., Mlynárová, L., and Nap, J. P. 2000. Detailed characterization of the posttranscriptional gene-silencing-related small RNA in a GUS gene-silenced tobacco RNA. RNA 6:1445-1454.

Lindbo, J. A., Silva-Rosales, L., Proebsting, W. M., and Dougherty, W. G. 1993. Induction of a highly specific antiviral state in transgenic plants: Implications for regulation of gene expression and virus resistance. Plant Cell 5:1749-1759.

Lindbo, J. A., Fitzmaurice, W. P., and della-Cioppa, G. 2001. Virus-mediated reprogramming of gene expression in plants. Curr. Opin. Plant Biol. 4:181-185.

Marathe, R., Anandalakshmi, R., Smith, T. H., Pruss, G. J., and Vance, V. B. 2000. RNA viruses as inducers, suppressors and targets of posttranscriptional gene silencing. Plant Mol. Biol. 43:295-306.

Matthews, R. E. F. 1991. Plant Virology. 3rd ed. Academic Press, San Diego, CA, U.S.A.

Matzke, M. A., Matzke, A. J. M., Pruss, G. J., and Vance, V. B. 2001. RNA-based silencing strategies in plants. Curr. Opin. Genet. Dev. 11:221-227.

Mette, M. F., Aufsatz, W., van der Winden, J., Matzke, M. A., and Matzke, A. J. M. 2000. Transcriptional silencing and promoter methylation triggered by double-stranded RNA. EMBO (Eur. Mol. Biol. Organ.) J. 19:5194-5201.

Montgomery, M. K., Xu, S., and Fire, A. 1998. RNA as a target of double-stranded RNA-mediated genetic interference in Caenorhabditis elegans. Proc. Natl. Acad. Sci. U.S.A. 95:15502-15507.

Mourrain, P., Beclin, C., Elmayan, T., Feuerbach, F., Godon, C., Morel, J. B., Jouette, D., Lacombe, A. M., Nikic, S., Picault, N., Remoue, K., Sanial, M., Vo, T. A., and Vaucheret, H. 2000 Arabidopsis SGS2 and $S G S 3$ genes are required for posttranscriptional gene silencing and natural virus resistance. Cell 101:533-542.

Owens, R. A., Steger, G., Hu, Y., Fels, A., Hammond, R. W., and Riesner, D. 1996. RNA structural features responsible for potato spindle tuber viroid pathogenicity. Virology 222:144-158.

Papaefthimiou, I., Hamilton, A. J., Denti, M. A., Baulcombe, D. C., Tsagris, M., and Tabler, M. 2001. Replicating potato spindle tuber viroid is accompanied by short RNA fragments that are characteristic of post-transcriptional gene silencing. Nucleic Acids Res. 29:2395-2400.

Pelissier, T., and Wassenegger, M. 2000. A DNA target of $30 \mathrm{bp}$ is sufficient for RNA-directed DNA methylation. RNA 6:55-65.

van Blockland, R., van der Geest, N., Mol, J. N. M., and Kooter, J. M. 1994. Transgene-mediated suppression of chalcone synthase expression in Petunia hybrida results from an increase in RNA turnover. Plant J. 6:861-877.

Vaucheret, H., and Fagard, M. 2001. Transcriptional gene silencing in plants: Targets, inducers and regulators. Trends Genet. 17:29-35.

Wassenegger, M., Heimes, S., Riedel, L., and Sanger, H. L. 1994. RNAdirected de novo methylation of genomic sequences in plants. Cell 76:567-576.

Zamore, P. D., Tuschl, T., Sharp, P. A., and Bartel, D. P. 2000. RNAi: Double-stranded RNA directs the ATP-dependent cleavage of mRNA at 21 to 23 nucleotide intervals. Cell 101:25-33. 